\title{
"Opening" The Mesenchymal Stem Cell Tool Box
}

\author{
Fares Zeidán-Chuliáa \\ Mami Nodab
}

\section{ABSTRACT}

Adult mesenchymal stem cells (MSCs) are adherent stromal cells able to self-renew and differentiate into a wide variety of cells and tissues. MSCs can be obtained from distinct tissue sources and have turned out to be successfully manipulated in vitro. As adult stem cells, MSCs are less tumorigenic than their embryonic correlatives and posses another unique characteristic which is their almost null immunogenicity. Moreover, these cells seem to be immunosuppressive in vitro. These facts together with others became MSCs a promising subject of study for future approaches in bioengineering and cell-based therapy. On the other hand, new strategies to achieve long-term integration as well as efficient differentiation of these cells at the area of the lesion are still challenging, and the signalling pathways ruling these processes are not completely well characterized. In this review, we are going summarize the general landscape and current status of the MSC tool as well as their wide potential in tissue engineering, from neuronal to tooth replacement. Highlights and pitfalls for further clinical applications will be discussed. (Eur J Dent 2009;3:240-249)
\end{abstract}

Key words: Adult mesenchymal stem cell; Dental pulp; Differentiation; Cell-based therapy; Tissue engineering; Tooth replacement.

\section{INTRODUCTION}

Stem cells are defined as immature cells able to proliferate, self-renew and differentiate into several more committed cellular types and

\footnotetext{
a Medical Biochemistry and Developmental Biology, Institute of Biomedicine, University of Helsinki, Finland.

b Laboratory of Pathophysiology, Graduate School of Pharmaceutical Sciences, Kyushu University, Fukuoka, Japan.

Corresponding author: Fares Zeidán Chuliá Department of Medical Biochemistry and Developmental Biology Institute of Biomedicine, Biomedicum Helsinki Haartmaninkatu 8, P.0.Box 63, FIN-00014, University of Helsinki, Finland

Phone: +358919125147

E-mail: fzchulia.biomedagmail.com
}

tissues. ${ }^{1}$ These cells could be generally classified in embryonic stem cells (ESCs) which are considered pluripotent thanks to their capability to give rise to all kinds of cells and adult stem cells. These last ones are just multipotent because their differentiation potential is restricted to certain cell lineages. ESCs are derived from the early mammalian embryo at the blastocyst stage (Figure 1) and under specific culture conditions they can undergo unlimited expansion in vitro and differentiation. ${ }^{2}$ On the contrary, adult stem cells are available from many tissues such as brain, bone, adipose tissue, umbilical cord blood, deciduous teeth, synovium, blood vessels and blood. ${ }^{3-5}$ Adult mesenchymal stem cells (MSCs) are at the moment highly considered as a cell-based 
therapeutic tool for a diverse range of clinical purposes. MSCs, in addition to their multipotency, are easy to isolate and culture in vitro and they do not apparently represent an ethical issue based on their source of origin (Table 1).

\section{MSCS: BIOLOGICAL BACKGROUND}

Mesenchymal stromal cells (MSCs) are multipotent adult stem cells, nonhematopoietic, with mesodermal and neuroectodermal origin. They can be found in several and perhaps most postnatal organs and tissues like adipose tissue, dental pulp, umbilical cord and especially in the bone marrow (BM) which appears to be the most often used source (Figure 2). MSCs are able to differentiate into cells of mesodermal origin like adypocites, chondrocytes or osteocytes, but they can also give rise to representative lineages of the three embryonic layers. ${ }^{6}$ For instance, it is well known that MSCs posses an extended degree of plasticity compared to other adult stem cell populations, including the ability to differentiate in vitro into non-mesodermal cell types such as neurons and astrocytes. ${ }^{7}$

MSCs can easily be isolated based on plastic adherence properties but the lack of one unique specific marker still represents a challenge for researchers. That is the reason why a general

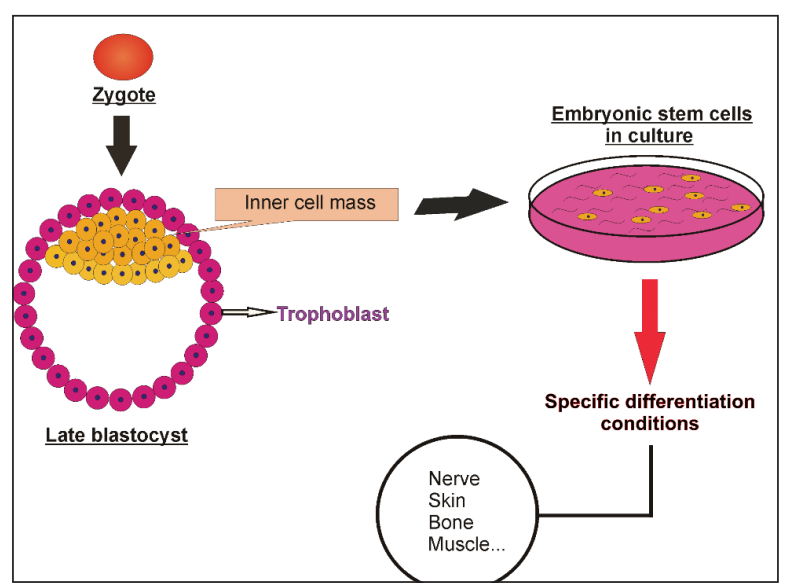

Figure 1. Embryonic stem cells (ESCs) are pluripotent cells derived from the early mammalian embryo at the blastocyst stage which can undergo unlimited expansion in vitro and differentiation into any kind of cell lineage, under specific culture conditions.

Table 1. ESCs vs. MSCs.

\begin{tabular}{lccccc}
\hline CELLS & Origin & Plasticity & Expansion & Tumorigenic & Ethical obstacles \\
\hline ESCs & Embryo & Pluripotent & Unlimited & Yes & Yes \\
MSCs & Adult tissues & Multipotent & Determined & No & No \\
\hline
\end{tabular}

rank of positive and negative surface markers has been used to ensure homogeneity of the isolation; meaning the presence of CD73, CD90, CD105 and lack of characteristic hematopoietic markers such as CD14, CD19, CD34, CD45 and HLA-DR, in addition to representative endothelial markers like CD318-10 (Table 2).

\section{IMMUNOMODULATORY CAPACITY OF}

\section{MSCS}

Stem cell-based therapy is generally linked to immunorejection problems when the used stem cell-derived tissue is not close or does not match the patient's one. Several approaches were tried to solve this major issue. Perhaps, the most challenging one was to reprogram adult somatic cells into the pluripotent stage liPSCs or induced pluripotent stem cells). Takahashi and Yamanaka11 showed that mouse embryonic and adult fibroblasts are able to acquire similar properties to ESCs after retroviral introduction of genes encoding four transcription factors: 0 ct3/4, Sox2, Klf4 and c-Myc. ${ }^{11-13}$ In fact, the tendency was to reduce the number of required genes to the minimum. Recently, Zhou et $\mathrm{al}^{14}$ were able to generate protein-induced pluripotent stem cells (piPSCs) from murine embryonic fibroblasts just by using recombinant proteins and consequently,

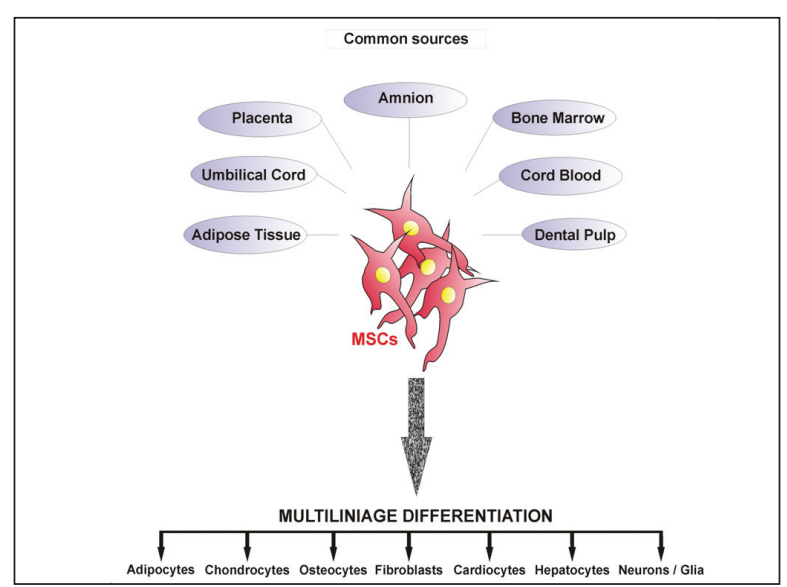

Figure 2. Mesenchymal stem cells (MSCs) can be isolated from distinct adult tissue sources. These cells have shown a great plasticity, being able to undergo differentiation into representative cell lineages of the three embryonic layers. 
avoiding any risk of changing the target cell genome by exogenous genetic modification.

MSCs represent an alternative route to avoid immunorejection since they are immunoprivileged and posses immunomodulatory properties. ${ }^{15,16}$ MSCs are considered immunoprivileged because they are able to be transplanted across major histocompatibility complex $(\mathrm{MHC})$ barriers making immunosupression of patient recipients unnecessary. These cells escape detection from immune system thanks to their low expression of MHC class I and the complete lack of MHC class II expression. ${ }^{17-19}$ Their immunomodulatory properties are not yet fully characterized even though it seems to implicate inhibition of proliferation of T cells and consecutive suppression of $T$ cells antigen-primed cytolytic effects. ${ }^{20,21}$

\section{SOURCES FOR MSCS: VERY SIMILAR OR REALLY DIFFERENT?}

In principle, MSCs can be isolated from different sources: Amnion, placenta, bone marrow (BM), umbilical cord and cord blood, adipose tissue and dental pulp are the most common ones (Figure 2). Moreover, these cells are available in virtually all post-natal tissues. There, they occupy a perivascular niche to support and maintain different connective and skeletal tissues. ${ }^{22}$ This fact makes very probable that other new sources may come up in the future since MSCs obtained from different places show close phenotypic characteristics. However, it is still unclear whether we may be dealing with the same MSCs or not because proliferation and differentiation capabilities in the presence of different growth factor stimulus do differ depending on the source of origin. For instance, bone marrow mesenchymal stem cells (BM-MSCs) have a tendency to loose their proliferative potential with

Table 2. General surface markers for MSCs.

\begin{tabular}{lc}
\hline Positive (+) & Negative (-) \\
\hline CD73 & CD14 \\
CD90 & CD19 \\
CD105 & CD31 \\
& CD34 \\
& CD45 \\
& HLA-DR \\
\hline
\end{tabular}

age and it is notorious the lost of differentiation capabilities after age $20 .{ }^{23}$ On the contrary, it has been shown that mesenchymal stem cells from the dental pulp (DPSCs) have higher proliferation index and growth potential even though both stem cell populations (BM-MSCs and DPSCs) still express very close surface markers such as Stro1, CD44, 3G5, CD146 and CD106. ${ }^{23}$ As a matter of fact, Wagner et $\mathrm{al}^{24}$ performed a gene expression profile study of MSCs coming from different origins (bone marrow, adipose tissue and cord blood) and compared them to HS68 fibroblasts. They showed that, though MSCs coming from different donors and exposed to the same culture conditions gave rise to a stable and reproducible gene expression profile, MSCs from different sources or cultured with different procedures differentially expressed many genes. On the contrary, no differences were found in a subset of 22 surface antigen markers suggesting that MSCs from different origin may share common phenotypic and receptor expression but indeed, they seem to be distinct at the genetic level. Peculiar differences are also seen in their differentiation potential where certain MSCs have been reported to show either tendencies or difficulties to differentiate into specific cellular lineages. For instance, DPSCs predominantly differentiate into bone and neurons ${ }^{25,26}$ and it has already been described unsuccessful trials for adipogenic differentiation in umbilical cord mesenchymal stem cells (UC-MSCs). ${ }^{27}$ Taking all these facts together we may conclude that even general biological characteristics of MSCs coming from different sources are common and comparable, major differences come up in terms of expansion and differentiation potential which should be taken under consideration before future clinical and therapeutic approaches.

THE DENTAL PULP STEM CELL NICHE

After injury, the dental pulp (Figure 3) plays a major role in tooth regeneration by participating in a process called reparative dentinogenesis, where cells create and accumulate new dentin matrix to repair the damaged area. ${ }^{28}$ Bigger traumas or advanced caries, for instance, can eventually cause the death of the pre-existing population of odontoblast. ${ }^{29}$ As consequence, new odontoblasts are recruited in order to differentiate at the injured area and to form reparative dentine, also 
known as osteodentine. This early mineralized tissue preserves the pulp integrity and serves as protective barrier upon the injury..$^{30}$ Then, one can speculate that dentinogenic progenitors may be located in that area of the dental pulp and in fact, some studies have already showed the existence of a population of putative post-natal stem cells or dental pulp stem cells (DPSCs) which may play a relevant role in reparative dentine formation. ${ }^{31}$ DPSCs can be considered as a heterogeneous population of MSCs since the dental pulp is composed from both mesenchymal and ectodermic components. Probably, they may be located in the perivascular area of the pulp as expression of characteristic markers suggest. For instance, VCAM-1 and a-smooth-muscle actin are positively expressed in these cells. ${ }^{32}$ Despite of the multipotential capabilities of these cells and even though their primary commitment seem to be the production of mineralized tissue, ${ }^{33}$ DPSCs have been shown to be able to generate functionally active neurons under determined environmental conditions. $^{25}$ This neuronal differentiation potential together with their accessibility makes DPSCs a good candidate of study for future cell-based therapy in spinal cord injury and neurodegenerative diseases.

\section{THERAPEUTIC APPLICATIONS OF MSCS: THE TOOL BOX}

MSCs exhibit a great potential for cell-based therapy in several diseases of different nature. Basically, these cells have a set of characteristics that somehow makes them adequate for clinical trials. They have an optimal expansion

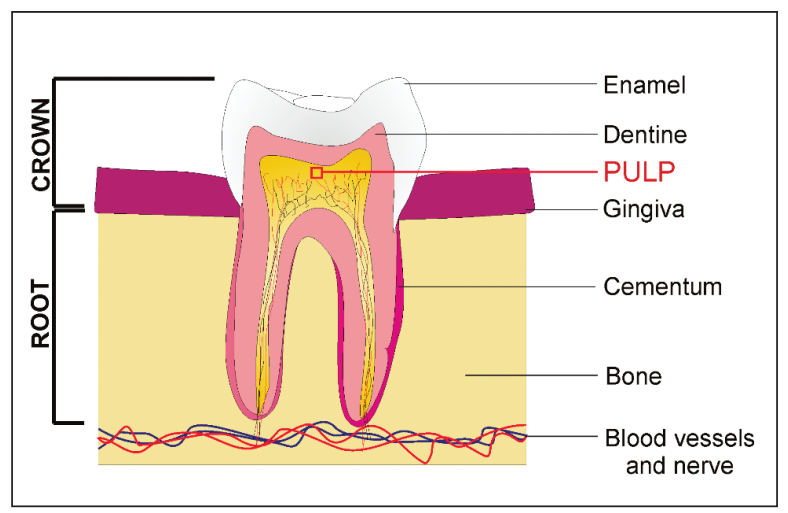

Figure 3. The human dental pulp contains a population of putative post-natal stem cells or dental pulp stem cells (DPSCs) with multipotential capabilities. After severe injury, the dental pulp stem cell niche may play a critical role in reparative dentine formation of the tooth. potential and genetic stability, there are really well established protocols of isolation and new sources keep on coming up apart from the already existing ones. Moreover, MSCs are able to migrate to areas of tissue damage in immunoprivileged conditions and posses immunosuppressive properties. All these advantages have allowed successful MSC transplantations (both autologous and heterologous). ${ }^{34-36}$ The current scenario of directly transplanting MSCs in vivo to different disease animal models and straight to the injured sites is changing nowadays. Recent progresses in nanotechnology and a better understanding of the molecular pathways that control the differentiation program made possible the combination of biocompatible scaffolds with MSCs, for instance. Genetic regulation of the cells within the scaffold, in order to achieve secretion of specific proteins that may benefit cell integration and tissue repair, would be doable with this new combination of strategies. ${ }^{37-39}$

\section{Treatment of neurological disorders}

A number of studies have already shown that MSCs are able to differentiate into nonmesenchymal lineages as a result of their great plasticity. These multipotent cells are able to give rise to both neurons and astrocytes in vitro and in vivo. ${ }^{40,41}$ Probably, the most important aspect for the use of these cells in neurological cell-based treatments was achieved when direct transplantation of MSCs into a rodent brain stroke model resulted to be safe and indeed improved functional deficits associated with the insult. ${ }^{42}$ One can speculate then, that MSCs may be the most feasible option to treat brain stroke insults and its devastating consequences in humans. Several trials were performed in other neurological disease models. Mazzini et al,43 for instance, started experiments with MSCs in the context of amyotrophic lateral sclerosis (ALS); a severe disease that leads to specific loss of motor neurons. As a result, a chronic decline in muscle functionality ends up in gradual paralysis of the patient. Mazzini et al ${ }^{43}$ implanted autologous BMMSCs in the spinal cord of monitored patients with ALS demonstrating tolerance and most importantly, safety of the procedure.

In general, different neurodegenerative states were taken on consideration for therapeutic 
approaches of neuronal circuitry; Parkinson's disease, Hungtinton's disease, multiple sclerosis and Alzheimer's disease are some examples.

\section{Spinal cord fusion}

A variety of cell transplantation approaches have been tested in different spinal cord injury models. Spinal cord injury treatment is one of the areas with bigger expectations for stem cellbased therapy. Lesions at the spinal cord triggers a number of biochemical cascades that are linked to progressive reduction in blood supply to the injured site. This event actually multiplies the extent of damaged tissue. In parallel, proliferation of fibroblasts together with endothelial and glial cells (astrocytes and microglia) at the injured area eventually constituting a biological scar that will act as both physical and chemical wall. ${ }^{44}$ Moreover, axonal growth and its guidance are prevented since both Schwann cells and neurotrophic factor are lacking and production of post-injury myelinassociated proteins is enhanced. Those molecules (for instance, Nogo-A) act as inhibitors of neurite outgrowth in the central nervous system. ${ }^{45}$ As a final result, all these events lead to a deficient regenerative capacity after trauma and the biggest obstacle for the development of definitive spinal cord injury treatments. The use of MSCs for the treatment of spinal cord injury seems to be an exciting option. In fact, it has already been described that transplanted MSCs led to a large numbers of surviving cells and formed guiding strands in the injured spinal cord. ${ }^{46}$ To repair neural networks, these cells should in addition demonstrate integration into the injured host tissue, potential to make synapses with host neurons as well as capabilities to achieve the specific required neural phenotype that is missing because of the disease process. We have to remember that MSC differentiation into undesired tissues has been reported as well. This makes crucially necessary the acquisition of strong biological knowledge about the behaviour and differentiation program of these cells, before any clinical trial could be performed in humans. ${ }^{47}$

\section{Kidney repair}

Different adult stem cells have been shown to differentiate into mature kidney cells, opening the question whether post-natal stem cells may be a potential tool for renal repair after systemic administration. Some studies in different models of kidney injury have suggested a role of resident bone marrow stem cells in kidney repair. ${ }^{48,49}$ Poulsom et $\mathrm{al}^{50}$ showed in mice that, after receiving bone marrow transplantation, circulating stem cells could be recruited to the site of injury overcoming acute kidney failure. Since the bone marrow (BM) contains at least a couple of known stem cell populations, haematopoietic stem cells (HSCs) and MSCs, these last ones may be responsible for improvement in a renal damage scenario, even though it remains unclear the actual number of MSCs in the adult kidney and whether they would be the only sufficient population of stem cells involved in the recovery. Despite the discrepancies about the mechanism, MSCs have been reported to protect against chemical-induced toxicity (cisplatin and glycerol) in mice, and in case of glycerol, MSC mobilization into the damaged kidney seemed to be dependent on the presence of $C D^{44}$. Kidneys damaged by injection of glycerol overexpressed hyaluronic acid (HA) and MSCs isolated from mice lacking $C D^{44}$, the receptor for $\mathrm{HA}$, were unable to migrate to injured sites of the kidneys. ${ }^{51,52}$ On the contrary, other chronic disease models showed no association between MSCs and improvement in renal function and/or animal survival. ${ }^{53}$ Nevertheless, additional knowledge about MSC transmigration mechanisms and differentiation into renal cells is required in order to consider MSCs as a future cellular source for kidney repair.

\section{Joint regeneration in rheumatic diseases}

Joint degeneration usually comes as a parallel event to degenerative arthritis losteoarthritis, OAl or rheumatoid arthritis (RA). Like other autoimmune diseases, they develop as a result of immunologic instability and loss of tolerance. Then, the immune system starts to react against self structures and tissues of the organism leading to gradual reduction of extracellular matrices in joint cartilage and bone. In these cases, therapy is focused in alleviating symptoms and/or changing the disease progress but never restores joint structure and functionality. Moreover, resistance for conventional therapy of anti-inflammatory and immunosuppressive drugs has been reported in some patients, making 
necessary the use of extremely high doses which are normally associated to side effects. Therefore, in these particular cases, BM restoration is recommended. ${ }^{54}$ It has already been shown that chondrogenic activity of MSCs is clearly reduced in patients with advanced osteoarthritisis. ${ }^{55}$

In fact, MSCs has been proposed as cell candidates for tissue engineering approaches in joint cartilage and bone defects repair, mainly because of their ability to substitute chondrocytes and immunomodulatory properties. Immunoprivileged status of MSCs became this particular type of stem cell an option to consider for allogeneic transplants with the advantages of an autologous one but it is still on debate whether the plasticity and differentiation potential remains the same in both cases. ${ }^{56,57}$ Their capabilities of creating new joint tissues and secreting different bioactive factors provide the adequate regenerative environment.58 Among all possible molecules and pathways modulating osteogenic differentiation, SOX9 seems to be critical. Tsuchiya et al59 showed that in BM derived-MSCs, the expression of exogenous SOX9 led to increased proteoglycan deposition. It has also been described that WNT signalling controls MSC fate decisions and this role is probably played in cooperation with other signalling pathways such as TGF- $\beta$ and BMPs. ${ }^{60-}$ 62 Nowadays, treatment of cartilage trauma coexists with almost null regenerative potential and for that purpose MSCs seem to be a good option for human tissue engineered cartilage, in combination with new nanotechnological tools, biomaterials and different growth factors that may help propagation, integration and differentiation of such cells. ${ }^{63}$

\section{Therapy for cardiac disease}

Cardiovascular failure is the leading cause of death worldwide. ${ }^{64}$ Most of the current therapies just delay progression mainly because of heart's weak capacity to self-regenerate. ${ }^{65}$ Since heart failure is directly linked to cardiomyocyte death and loss of myocardial cell mass, stem cell therapy has strongly come up as a novel therapeutic option to treat cardiac disease. ${ }^{66,67}$ Different cells such as hematopoietic stem cells, endothelial progenitor cells, cardiac stem cells, ES cells and MSCs were on debate as the most adequate one for that approach; especially, adult bone marrow derived stem cells which were reported to improve myocardial function after infarction. ${ }^{68,69}$ In fact, results from different laboratories demonstrated that MSCs, under specific conditions lexposition to grow factors and/or diverse chemical compounds), are able to give rise to cardiomyocyte-like cells. ${ }^{70-72}$ These differentiation potential has also been described in vivo but at lower rates and one can never exclude the possibility of getting additional unwished differentiated cell types. For instance, Breitbach et al described the development of encapsulated areas with calcifications and/or ossification at myocardial sites after MSC transplantation in a cryo-infarction animal model. ${ }^{47,73}$ Indeed, several questions remain with no answer at many levels and whether MSCs may be the best model for cardiovascular repair is still to be shown.

\section{Skin regeneration}

Wound healing is a complicated biological process where several kinds of cells are required, extracellular matrix (ECM) deposition is needed and different regulatory events such as angiogenesis should be well coordinated. ${ }^{74,75}$ This process gets relevant when it comes to patients suffering diabetes. ${ }^{76,77}$ Foot ulcers are relatively common among patients with diabetes and they easily get infected. If the infection is not properly treated and finally extends, it could lead to foot amputation for septic gangrene. Wound healing is an extremely important event in burned patients too. In this scenario, infections are also the most general complication especially in highest degree burns. Two stem cell niches are probably involved in the repair of the damaged tissue: stem cells from the injured tissue itself and/or migratory stem cells from bone marrow (MSCs and hematopoitic stem cells). Thus, MSCs may migrate from bone marrow to damaged tissues in order to reconstitute skin in cutaneous wounds. ${ }^{78}$ Burn wound animal models have already been tried demonstrating that tissueengineered skin containing MSCs can accelerate wound healing successfully. Wounds grafted with MSCS showed better epidermal formation and increased vascularisation. ${ }^{79}$ In fact, Wu et al80 showed that BM-MSCs are able to promote wound repair through differentiation and production of proangiogenic factors like vascular endothelial growth factor (VEGF) and angiopoietin-1. Better 
understanding about this mechanism may contribute to develop novel therapies for severe cutaneous status like the ones mentioned above as well engineering new skin substitutes.

\section{Tooth engineering}

Tooth loss is often associated with both physiological and pathological causes that include aging, trauma, dental caries, periodontal diseases as well as genetic reasons. In addition to physical limitations, tooth loss affects facial esthetic and decreases quality of life. ${ }^{81}$ Nowadays, different research groups are working in the development of new stem-cellbased tissue engineering approaches for tooth regeneration..$^{82-84}$ Recent strategies focus on combination of several scaffolding biomaterials, where cells are seeded, together with controlled release of signalling cues for stem cells. ${ }^{37,85,86}$ These kinds of polymer scaffolds, like polyglycolic acid (PGA) or poly (lactic-co-glycolic) acid (PLGA), are biodegradable and permit implantation of cell-scaffold constructs on the host, revealing a promising option for tooth regeneration. Besides, MSCs from dental pulp and bone marrow have been proposed as potential candidates for tooth engineering. Indeed, it was reported that both populations are able to successfully form different dental structures under specific conditions..$^{87-91}$ Moreover, Yu et al ${ }^{92}$ concluded that DPSCs showed the highest odontogenic capability under the same inductive microenvironment in comparison to bone marrow stromal stem cells. But despite of its potential, a number of obstacles such as shape, size and growth control of the new developing bio-engineered tooth and availability of dental epithelium as well as graft rejection in the jaws are still challenging researchers in the field..$^{93}$

\section{CONCLUSIONS}

Interest about novel stem cell-based therapies has exponentially been increasing over the past years, not only in the scientific community but also within the society. Indeed, stem cells seem to give the best chance for human tissue engineering and particularly, hMSCs, may be a great tool in regenerative medicine because of their ability to differentiate into a variety of specialized cells in addition to their immunoprivileged characteristics. However, caution is always recommended to ensure safety and success of clinical trials. More detailed data concerning biological and functional properties of MSCs is still required. In this review, we wanted to summarize the general landscape of the MSC tool box for bioengineering, which may provide in the future new therapeutic strategies for a range of diseases with no cure so far.

\section{ACKNOWLEDGEMENTS}

Fares Zeidán-Chuliá was supported by the Marie Curie Early Stage Research Training (EST) program at the University of Helsinki, Finland.

\section{REFERENCES}

1. Preston SL, Alison MR, Forbes SJ, Direkze NC, Poulsom $\mathrm{R}$, Wright NA. The new stem cell biology: something for everyone. J Clin Pathol: Mol Pathol 2003;56:86-96.

2. Thomson JA, Itskovitz-Eldor J, Shapiro SS, Waknitz MA, Swiergiel JJ, Marshall VS, Jones JM. Embryonic stem cell lines derived from human blastocysts. Science 1998;282:1145-1147.

3. Nakagami H, Morishita R, Maeda K, Kikuchi Y, Ogihara T, Kaneda Y. Adipose tissue-derived stromal cells as a novel option for regenerative cell therapy. J Atheroscler Thromb 2006;13:77-81.

4. Miura M, Gronthos S, Zhao M, Lu B, Fisher LW, Robey PG, Shi S. SHED: stem cells from human exfoliated deciduous teeth. Proc Natl Acad Sci USA 2003;100:5807-5812.

5. Lee OK, Kuo TK, Chen WM, Lee KD, Hsieh SL, Chen TH. Isolation of multipotent mesenchymal stem cells from umbilical cord blood. Blood 2004;103:1669-1675.

6. da Silva Meirelles L, Chagastelles PC, Nardi NB. Mesenchymal stem cells reside in virtually all post-natal organs and tissues. J Cell Sci 2006;119:2204-2213.

7. Meirelles Lda S, Nardi NB. Methodology, biology and clinical applications of mesenchymal stem cells. Front Biosci 2009;14:4281-4298.

8. Haniffa MA, Collin MP, Buckley CD, Dazzi F. Mesenchymal stem cells: the fibroblasts' new clothes? Haematologica 2009;94:258-263.

9. Horwitz EM, Le Blanc K, Dominici M, Mueller I, SlaperCortenbach I, Marini FC, Deans RJ, Krause DS, Keating A; the International Society for Cellular Therapy. Clarification of the nomenclature for MSC: The International Society for Cellular Therapy position statement. Cytotherapy 2005;7:393-395

10. Valtieri M, Sorrentino A. The mesenchymal stromal cell contribution to homeostasis. J Cell Physiol 2008;217:296300 
11. Takahashi K, Yamanaka S. Induction of pluripotent stem cells from mouse embryonic and adult fibroblast cultures by defined factors. Cell 2006;126:663-676.

12. Takahashi K, Tanabe K, Ohnuki M, Ichisaka T, Tomoda K Yamanaka $S$. Induction of pluripotent stem cells from adult human fibroblasts by defined factors. Cell 2007;131:861872.

13. Yamanaka S. A fresh look to iPS cells. Cell 2009;137:13-17.

14. Zhou H, Wu S, Joo J, Zhu S, Han D, Lin T, Trauger S, Bien G, Yao S, Zhu Y, Siuzdak G, Schöler H, Duan L, Ding S. Generation of induced pluripotent stem cells using recombinant proteins. Cell Stem Cell 2009, doi:10.1016/j. stem.2009.04.005

15. Uccelli A, Moretta L, Pistoia V. Immunoregulatory function of mesenchymal stem cells. Eur J Immunol 2006;36:25662573.

16. Aggarwal S, Pittenger MF. Human mesenchymal stem cells modulate allogeneic immune cell responses. Blood 2005; 105:1815-1822.

17. Rasmusson I. Immune modulation by mesenchymal stem cells. Exp Cell Res 2006;312:2169-2179.

18. Chang CJ, Yen ML, Chen YC Chien CC, Huang HI, Bai $\mathrm{CH}$, Yen BL. Placenta-derived multipotent cells exhibit immunosuppressive properties that are enhanced in the presence of interferon-y. Stem Cells 2006;24:2466-2477.

19. Le Blanc K, Tammik C, Rosendhal K, Zetterberg E, Ringdén 0 . HLA expression and immunologic properties of differentiated and undifferentiated mesenchymal stem cells. Exp Hematol 2003;31:890-896.

20. Beyth S, Borovsky Z, Mevorach D, Liebergall M, Gazit Z, Aslan H, Galun E, Rachmilewitz J. Human mesenchymal stem cells alter antigen-presenting cell maturation and induce T-cell unresponsiveness. Blood 2005;105:22142219.

21. Rasmusson I, Ringdén 0 , Sundberg B, Le Blanc $K$. Mesenchymal stem cells inhibit the formation of cytotoxic T lymphocytes, but not activated cytotoxic T lymphocytes or natural killer cells. Transplantation 2003; 76:1208-1213.

22. Taivan M, Zheng B, Oberlin E, Crisan M, Sun B, Huard J, Peault B. The vascular wall as a source of stem cells. Ann NY Acad Sci 2005;1044:41-50.

23. Shi S, Bartold PM, Miura M, Seo BM, Robey PG, Gronthos S. The efficacy of mesenchymal stem cells to regenerate and repair dental structures. Orthod Craniofac Res 2005;8:191199.

24. Wagner W, Wein F, Seckinger A, Frankhauser $M$, Wirkner U, Krause U, Blake J, Schwager C, Eckstein V, Ansorge W, Ho AD. Comparative characteristics of mesenchymal stem cells from human bone marrow, adipose tissue, and umbilical cord blood. Exp Hematol 2005;33:1402-1416.
25. Arthur A, Rychkov G, Shi S, Koblar SA, Gronthos S. Adult human dental pulp stem cells differentiate toward functionally active neurons under appropriate environmental cues. Stem Cells 2008;26:1787-1795.

26. Zhang W, Walboomers XF, Van Kuppevelt TH, Daamen WF, Van Damme PA, Bian Z, Jansen JA. In vivo evaluation of human dental pulp stem cells differentiated towards multiple lineages. J Tissue Eng Regen Med 2008;2:117-125.

27. Bieback K, Kern S, Kocaömer A, Ferlik K, Bugert P. Comparing mesenchymal stromal cells from different human tissues: bone marrow, adipose tissue and umbilical cord blood. Biomed Mater Eng 2008;18:S71-S76.

28. Mitsiadis TA, Rahiotis C. Parallels between tooth development and repair: conserved molecular mechanisms following carious and dental injury. J Dent Res 2004;83:896902.

29. Arana-Chavez VE, Massa LF. Odontoblast: the cells forming and maintaining dentine. Int J Biochem Cell Biol 2004;36:1367-1373.

30. Murray PE, About I, Franquin JC, Remusat M, Smith AJ. Restorative pulpal and repair responses. J Am Dent Assoc 2001;132:482-491.

31. Huang GT, Sonoyama W, Liu Y, Liu H, Wang S, Shi S. The hidden treasure in apical papilla: the potential role in pulp/dentin regeneration and bioroot engineering. $J$ Endod 2008;34:645-651.

32. Gronthos S, Mankani M, Brahim J, Robey PG, Shi S. Postnatal human dental pulp stem cells (DPSCs) in vitro and in vivo. Proc Natl Acad Sci USA 2000;97:13625-13630.

33. Wei X, Ling J, Wu L, Liu L, Xiao Y. Expression of mineralization markers in dental pulp cells. $J$ Endod 2007;33:703-708.

34. Giordano A, Galderisi U, Marino IR. From the laboratory bench to the patient's bedside: an update on clinical trials with mesenchymal stem cells. J Cell Physiol 2007;211:2735.

35. Le Blanc K, Pittenger M. Mesenchymal stem cells: progress toward promise. Cytotherapy 2005;7:36-45.

36. Caplan Al. Why are MSCs therapeutic? New data: new insight. J Pathol 2009;217:318-324.

37. Moioli EK, Clark PA, Xin X, Lal S, Mao JJ. Matrices and scaffolds for drug delivery in dental, oral and craniofacial tissue engineering. Adv Drug Deliv Rev 2007;59:308-324.

38. Oh S, Brammer KS, Li YS, Teng D, Engler AJ, Chien S, Jin S. Stem cell fate dictated solely by altered nanotube dimension. Proc Natl Acad Sci USA 2009;106:2130-2135.

39. Tuan RS, Boland G, Tuli R. Adult mesenchymal stem cells and cell-based tissue engineering. Arthritis Res Ther 2003;5:32-45 
40. Zietlow R, Lane EL, Dunnett SB, Rosser AE. Human stem cells for CNS repair. Cell Tissue Res 2008;331:301-322.

41. Rosser AE, Zietlow R, Dunnett SB. Stem cell transplantation for neurodegenerative diseases. Curr Opin Neurol 2007;20:668-692.

42. Chen J, Li Y, Wang L, Lu M, Zhang X, Chopp M. Therapeutic benefit of intracerebral transplantation of bone marrow stromal cells after cerebral ischemia in rats. $J$ Neurol Sci 2001;189:49-57.

43. Mazzini L, Fagioli F, Boccaletti R, Mareschi K, Oliveri G, Oliveri C, Pastore I, Marasso R, Madon E. Stem cell therapy in amyotrophic lateral sclerosis: a methodological approach in humans. Amyotroph Lateral Scler Other Motor Neuron Disord 2003;4:158-161.

44. Leme RJ, Chadi G. Distant microglial and astroglial activation secondary to experimental spinal cord lesion. Arq Neuropsiquiatr 2001;59:483-492.

45. KarnezisT, Mandemakers W, McQualter JL, Zheng B, Ho PP, Jordan KA, Murray BM, Barres B, Tessier-Lavigne $M$, Bernard CC. The neurite outgrowth inhibitor Nogo $A$ is involved in autoimmune-mediated demyelination. Nat Neurosci 2004;7:736-744.

46. Hofstetter CP, Schwarz EJ, Hess D, Widenfalk J, El Manira A, Prockop DJ, Olson L. Marrow stromal cells form guiding strands in the injured spinal cord and promote recovery. Proc Natl Acad Sci USA 2002;99:2199-2204.

47. Breitbach M, Bostani T, Roell W, Xia Y, Dewald O, Nygren JM, Fries JW, Tiemann K, Bohlen H, Hescheler J, Welz A, Bloch W, Jacobsen SE, Fleischmann BK. Potential risks of bone marrow cell transplantation into infarcted hearts. Blood 2007;110:1362-1369.

48. Kale S, Karihaloo A, Clark PR, Kashgarian M, Krause DS, Cantley LG. Bone marrow stem cells contribute to repair of the ischemically injured renal tubule. $J$ Clin Invest 2003;112:42-49.

49. Gupta S, Verfaillie C, Chmielewski D, Kim Y, Rosenberg ME. A role for extrarenal cells in the regeneration following acute renal failure. Kidney Int 2002;62:1285-1290.

50. Poulsom R, Forbes SJ, Hodivala-Dilke K, Ryan E, Wyles S, Navaratnarasah S, Jeffery R, Hunt T, Alison M, Cook T, Pusey C, Wright NA. Bone marrow contributes to renal parenchymal turnover and regeneration. J Pathol 2001;195:229-235.

51. Morigi $M$, Introna $M$, Imberti $B$, Corna D, Abbate $M$, Rota $C$, Rottoli D, Benigni A, Perico N, Zoja C, Rambaldi A, Remuzzi A, Remuzzi G. Human bone marrow mesenchymal stem cells accelerate recovery of acute renal injury and prolong survival in mice. Stem Cells 2008;26:2075-2082.
52. Herrera MB, Bussolati B, Bruno S, Morando L, MaurielloRomanazzi G, Sanavio F, Stamenkovic I, Biancone L, Camussi G. Exogenous mesenchymal stem cells localize to the kidney by means of CD44 following acute tubular injury. Kidney Int 2007;72:430-441.

53. Ninichuk V, Gross O, Segerer S, Hoffmann R, Radomska E, Buchstaller A, Huss R, Akis N, Schlöndorff D, Anders HJ. Multipotent mesenchymal stem cells reduce interstitial fibrosis but do not delay progression of chronic kidney disease in collagen4A3-deficient mice. Kidney Int 2006;70:121-129.

54. Rosa SB, Voltarelli JC, Chies JA, Pranke P. The use of stem cells for the treatment of autoimmune diseases. Braz J Med Biol Res 2007;40:1579-1597.

55. Murphy JM, Dixon K, Beck S, Fabian D, Feldman A, Barry F. Reduced chondrogenic and adipogenic activity of mesenchymal stem cells from patients with advanced osteoarthritis. Arthritis Rheum 2002;46:704-713.

56. Gazdag AR, Lane JM, Glaser D, Forster RA. Alternatives to Autogenous Bone Graft: Efficacy and Indications. J Am Acad Orthop Surg 1995;3:1-8.

57. Müller I, Lymperi S, Dazzi F. Mesenchymal stem cell therapy for degenerative inflammatory disorders. Curr Opin Organ Transplant 2008; 13:639-644.

58. Caplan Al, Dennis JE. Mesenchymal stem cells as trophic mediators. J Cell Biochem 2006;98:1076-1084.

59. Tsuchiya H, Sugiura F, Ishiguro N. Chondrogenesis enhanced by overexpression of sox 9 gene in mouse bone marrow-derived mesenchymal stem cells. Biochem Biophys Res Commun 2003;301:338-343.

60. Ling L, Nurcombe V, Cool SM. Wnt signaling controls the fate of mesenchymal stem cells. Gene 2009;433:1-7.

61. Baksh D, Tuan RS. Canonical and non-canonical Wnts differentially affect the development potential of primary isolate of human bone marrow mesenchymal stem cells. $J$ Cell Physiol 2007;212:817-826.

62. Zhou S, Eid K, Glowacki J. Cooperation between TGFbeta and Wnt pathways during chondrocyte and adipocyte differentiation of human marrow stromal cells. $J$ Bone Miner Res 2004;19:463-470.

63. Raghunath J, Salacinski HJ, Sales KM, Butler PE, Seifalian AM. Advancing cartilage tissue engineering: the application of stem cell technology. Curr Opin Biotechnol 2005;16:503509.

64. Lopez AD, Mathers CD, Ezzati M, Jamison DT, Murray CJ. Global and regional burden of disease and risk factors, 2001: systematic analysis of population health data. Lancet 2006;367:1747-1757. 
65. Fonarow GC. Heart failure: recent advances in prevention and treatment. Rev Cardiovasc Med 2000;1:25-33, 54.

66. Fedak PW, Verma S, Weidel RD, Li RK. Cardiac remodeling and failure: from molecules to man (Part I). Cardiovasc Pathol 2005;14:1-11.

67. Strauer BE, Schannwell CM, Brehm M. Therapeutic potentials of stem cells in cardiac diseases. Minerva Cardioangiol 2009;57:249-267.

68. Laflamme MA, Murry CE. Regenerating the heart. Nat Biotechnol 2005;23:845-856.

69. Orlic D, Kajstura J, Chimenti S, Limana F, Jakoniuk I, Quaini F, Nadal-Ginard B, Bodine DM, Leri A, Anversa P. Mobilized bone marrow cells repair the infarcted heart, improving function and survival. Proc Natl Acad Sci USA 2001;98:10344-10349.

70. Erices AA, Allers Cl. Conget PA, Rojas CV, Minguell JJ. Human cord blood-derived mesenchymal stem cells home and survive in the marrow of immunodeficient mice after systemic infusion. Cell Transplant 2003;12:555-561.

71. Shim WS, Jiang S, Wong P, Tan J, Chua YL, Tan YS, Sin YK, Lim CH, Chua T, Teh M, Liu TC, Sim E. Ex vivo differentiation of human adult bone marrow stem cells into cardiomyocyte-like cells. Biochem Biophys Res Commun 2004;324:481-488.

72. Xu W, Zhang X, Qian H, Zhu W, Sun X, Hu J, Zhou H, Chen Y. Mesenchymal stem cells from adult human bone marrow differentiate into a cardiomyocyte phenotype in vitro. Exp Biol Med 2004;229:623-631.

73. Miyahara Y, Nagaya N, Kataoka M, Yanagawa B, Tanaka K, Hao H, Ishino K, Ishida H, Shimizu T, Kangawa K, Sano S, Okano T, Kitamura S, Mori H. Monolayered mesenchymal stem cells repair scarred myocardium after myocardial infarction. Nat Med 2006;12:459-465.

74. Martin P. Wound healing--aiming for perfect skin regeneration. Science 1997;276:75-81.

75. Singer AJ, Clark RA. Cutaneous wound healing. $N$ Engl $J$ Med 1999;341:738-746.

76. Andersen CA, Roukis TS. The diabetic foot. Surg Clin North Am 2007;87:1149-1177.

77. Armstrong DG, Lipsky BA. Diabetic foot infections: stepwise medical and surgical management. Int Wound J 2004;1:123132.

78. Li H, Fu X, Ouyang Y, Cai C, Wang J, Sun T. Adult bonemarrow-derived mesenchymal stem cells contribute to wound healing of skin appendages. Cell Tissue Res 2006;326:725-736.

79. Liu P, Deng Z, Han S, Liu T, Wen N, Lu W, Geng X, Huang $\mathrm{S}$, Jin Y. Tissue-engineered skin containing mesenchymal stem cells improves burn wounds. ArtifOrgans 2008;32:925931.

\section{July 2009 - Vol.3}

80. Wu Y, Chen L, Scott PG, Tredget EE. Mesenchymal stem cells enhance wound healing through differentiation and angiogenesis. Stem Cells 2007;25:2648-2659.

81. Amar $S$, Han X. The impact of periodontal infection on systemic diseases. Med Sci Monit 2003; 9(12):RA291-9.

82. Yen AH, Sharpe PT. Regeneration of teeth using stem cellbased tissue engineering. Expert Opin Biol Ther 2006;6:916.

83. Duailibi SE, Duailibi MT, Zhang W, Asrican R, Vacanti JP, Yelick PC. Bioengineered dental tissues grown in the rat jaw. J Dent Res 2008;87:745-750.

84. Ferreira CF, Magini RS, Sharpe PT. Biological tooth replacement and repair. J Oral Rehabil 2007;34:933-939.

85. Bianco $P$, Robey $P G$. Stem cells in tissue engineering. Nature 2001;414:118-121.

86. Rezwan K, Chen QZ, Blaker JJ, Boccaccini AR. Biodegradable and bioactive porous polymer/inorganic composite scaffolds for bone tissue engineering. Biomaterials 2006;27:3413-3431.

87. Yu J, Deng Z, Shi J, Zhai H, Nie X, Zhuang H, Li Y, Jin Y. Differentiation of dental pulp stem cells into regularshaped dentin-pulp complex induced by tooth germ cell conditioned medium. Tissue Eng 2006;12:3097-3105.

88. Gronthos S, Akintoye SO, Wang CY, Shi S. Bone marrow stromal stem cells for tissue engineering. Periodontol 2000 2006;41:188-195.

89. Liu H, Gronthos S, Shi S. Dental pulp stem cells. Methods Enzymol 2006;419:99-113.

90. Hu B, Unda F, Bopp-Kuchler S, Jimenez L Wang XJ, Haïkel Y, Wang SL, Lesot $\mathrm{H}$. Bone marrow cells can give rise to ameloblast-like cells. J Dent Res 2006;85:416-421.

91. Iohara K, Nakashima M, Ito M, Ishikawa M, Nakasima A, Akamine A. Dentin regeneration by dental pulp stem cell therapy with recombinant human bone morphogenetic protein 2. J Dent Res 2004;83:590-595.

92. Yu J, Wang Y, Deng Z, Tang L, Li Y, Shi J, Jin Y. Odontogenic capability: bone marrow stromal stem cells versus dental pulp stem cells. Biol Cell 2007;99:465-474.

93. Yu J, Shi J, Jin Y. Current approaches and challenges in making a bio-tooth. Tissue Eng Part B Rev 2008;14:307-319. 